The University of Maine

DigitalCommons@UMaine

Marine Sciences Faculty Scholarship

School of Marine Sciences

7-1-2005

\title{
Uncertainties of inherent optical properties obtained from semianalytical inversions of ocean color
}

\author{
Peng Wang \\ University of Maine \\ Emmanuel S. Boss \\ University of Maine, emmanuel.boss@maine.edu \\ Collin Roesler \\ Bigelow Laboratory for Ocean Sciences
}

Follow this and additional works at: https://digitalcommons.library.umaine.edu/sms_facpub

Part of the Marine Biology Commons

\section{Repository Citation}

Wang, Peng; Boss, Emmanuel S.; and Roesler, Collin, "Uncertainties of inherent optical properties obtained from semianalytical inversions of ocean color" (2005). Marine Sciences Faculty Scholarship. 158.

https://digitalcommons.library.umaine.edu/sms_facpub/158

This Article is brought to you for free and open access by DigitalCommons@UMaine. It has been accepted for inclusion in Marine Sciences Faculty Scholarship by an authorized administrator of DigitalCommons@UMaine. For more information, please contact um.library.technical.services@maine.edu. 


\title{
Uncertainties of inherent optical properties obtained from semianalytical inversions of ocean color
}

\author{
Peng Wang, Emmanuel S. Boss, and Collin Roesler
}

\begin{abstract}
We present a method to quantify the uncertainties in the in-water constituent absorption and backscattering coefficients obtained from an inversion of remotely sensed reflectance $\left(r_{\mathrm{rs}}\right)$. We first find a set of positive inversion solutions within a given uncertainty range around the values of the inverted $r_{\mathrm{rs}}$. The uncertainties of the solutions are then computed based on the statistics of these solutions. We demonstrate the uncertainty calculation algorithm using a specific semianalytic inversion model applied to both a field and a simulated data set. When the associated uncertainties are taken into account, the inverted parameters are generally within the uncertainties of the measured (or simulated) parameters, highlighting the success of the inversion and the method to obtain uncertainties. The specific inversion we use, however, fails to retrieve two spectral parameters within a usable range. The method presented is general and can be applied to all existing semianalytical inversion algorithms. (C) 2005 Optical Society of America

OCIS codes: $\quad 010.4450,280.0280$.
\end{abstract}

\section{Introduction}

The inherent optical properties (IOPs; the optical properties that are independent of the ambient light field ${ }^{1}$ ) with appropriate boundary conditions, determine the Sun-illuminated aquatic light field. IOPs include the absorption and backscattering coefficients. The apparent optical properties ${ }^{1}$ (AOPs) are connected to the IOPs by the equation of radiative transfer. ${ }^{1-2}$ Approximations to the radiative transfer equation (RTE) indicate that remotely sensed reflectance $\left(r_{\mathrm{rs}}\right.$, also referred to as ocean color, an AOP, see notations in Table 3 for symbols and definitions used in this paper) depends to first order on the absorption and backscattering coefficients. ${ }^{3-4}$ One goal in using ocean color inversions is to obtain the absorption and backscattering coefficients due to different in-water constituents by inverting $r_{\mathrm{rs}}$. The three main components of IOPs that are currently retrievable are phytoplankton absorption, combined absorption of colored dissolved organic matter (CDOM) and nonalgal particles (NAP), and particulate backscattering.

P. Wang and E. S. Boss (emmanuel.boss@maine.edu) are with the University of Maine, 5741 Libby Hall, Orono, Maine 044695741. C. Roesler is with the Bigelow Laboratory for Ocean Sciences, P.O. Box 475, West Boothbay Harbor, Maine 04575-0475.

Received 16 November 2004; accepted 3 January 2005.

0003-6935/05/194074- $12 \$ 15.00 / 0$

(C) 2005 Optical Society of America
Obtaining these IOPs is of importance as they relate to standing stocks and rate processes of important aquatic carbon pools. ${ }^{5-8}$

Semianalytical ocean-color inversion algorithms ${ }^{9-13}$ are based on approximate solutions to the RTE (the analytical part) and assumptions regarding the spectral shapes of IOPs (the empirical part). Unlike purely empirical algorithms, semianalytical algorithms are not limited to certain geographical regions or water type.

Currently, no accepted method exists for quantifying the uncertainties associated with the inversion products of semianalytical models, and their output has been reported without the associated error bars. Some general confidence intervals (e.g., not associated with each inverted $r_{\mathrm{rs}}$ ) have been estimated on the basis of sensitivity analysis on a subset of the data ${ }^{9,11-12}$ or the basis of the magnitude of residuals between the measured spectra and that constructed from the inverted IOPs. ${ }^{14}$ Without an estimate of the uncertainties in inversion products (e.g., IOPs) it is impossible either to propagate errors when inversion products are used as inputs into primary production and carbon models or to assess whether closure between remotely sensed estimates of IOPs and in-water IOPs has been achieved. In this paper we present a procedure to obtain uncertainty estimates for inverted IOPs obtained by semianalytical inversions. 


\section{Data and Methods}

\section{A. Data Sets}

\section{Simulated Data Set}

We demonstrate our approach using a synthetic data set developed by Z. P. Lee ${ }^{15}$ as part of the activities of the International Ocean Color Coordination Group (IOCCG) Ocean-Color Algorithms coordinating group. ${ }^{16}$ This data set contains both spectral IOPs based on observations and theoretical analysis of field data and the corresponding $r_{\mathrm{rs}}$ derived from the IOPS in which a radiative transfer model (Hydrolight, Sequoia Scientific) for a Sun at $30^{\circ}$ zenith angle was used. In total, there are 500 IOP and $r_{\mathrm{rs}}$ spectra in the synthetic data set that are freely available on the WWW.17 Wavelengths used for inversion of simulated data vary from 400 to $650 \mathrm{~nm}$ with a $10-\mathrm{nm}$ interval (number of wavelength, $m=26$ ). We assume the IOPs of the simulated data set to be error free.

\section{Field Data Set}

The field data set was collected during the summers of 2000 and 2001 as part of the Hyperspectral Coupled Ocean Dynamics Experiments (HyCODE) field experiment at the Mid-Atlantic Bight in the vicinity of the Long-term Ecological Observatory site (LEO15) off the coast of New Jersey in water depths of less than $25 \mathrm{~m} .{ }^{18}$

Radiometric quantities were collected with a Satlantic, Inc. HyperTSRB (Tethered Spectral Radiometer Buoy) that measured upwelling radiance at $0.66 \mathrm{~m}$ below the sea surface, $L_{u}(\lambda, 0.66 \mathrm{~m})$, and downwelling irradiance just above the sea surface, $E_{d}\left(\lambda, 0^{+} \mathrm{m}\right)$ between wavelengths of 400 and $800 \mathrm{~nm}$ at $1-n m$ resolution. To avoid the chlorophyll fluorescence contribution near $680 \mathrm{~nm}$, only $r_{\mathrm{rs}}$ between wavelengths of 412 and $650 \mathrm{~nm}$ are used as input for the inversion preformed in the current paper (number of wavelengths, $m=239$ ). Here we use a total of 31 independent IOP- $r_{\mathrm{rs}}$ match-up stations. A subset (year 2000) of these data (IOP and $r_{\mathrm{rs}}$ ) was used in previous studies. ${ }^{18,19}$

IOPs were measured with a free-falling slow descent rate optics platform (Slowdrop ${ }^{20}$ ). Absorption by dissolved and particulate materials and backscattering data were collected with 2 WETLabs ac-9s (one ac-9 with a $0.2-\mu \mathrm{m}$ prefilter, the other unfiltered) and a HOBILab Hydroscat-6, respectively. Data were collected and processed according to standard protocols. ${ }^{21}$ At each station the IOPs were collected as a series of consecutive vertical profiles. For match-up IOPs we chose the IOPs profile with least variability from the surface down to a depth equal to (absorption $)^{-1}$, from which approximately $90 \%$ of the signal emanates. ${ }^{22}$ For that profile the difference between maximum and minimum values is used to quantify the uncertainty in the observed IOP with the median being the expected value.

We use a simple analytical model for converting the radiance as measured by a TSRB to water-leaving radiance. $^{23}$ Above-surface remote-sensing reflec- tance, $R_{\mathrm{rs}}$, is then computed with the following relation:

$$
\begin{aligned}
R_{r s} & =\frac{L_{w}\left(\lambda, 0^{+}\right)}{E_{d}\left(\lambda, 0^{+}\right)}=C(\lambda) \frac{L_{w}(\lambda, 0.66 m)}{E_{d}\left(\lambda, 0^{+}\right)}, \\
C(\lambda) & =\frac{t}{n^{2}} \exp \left[0.66 k_{L}(\lambda)\right],
\end{aligned}
$$

where the diffuse attenuation $k_{L}$ is approximated by $a(\lambda) / \cos \theta_{\mathrm{s}}, a(\lambda)$ is the absorption coefficient, $n \approx$ 1.34 is the index of refraction of seawater, $t \approx 0.98$ is the radiance transmittance across the air-water interface, and $\theta_{\mathrm{s}}$ is the in-water solar zenith angle. We convert above-surface remote-sensing reflectance spectra $R_{\text {rs }}$ to below-surface spectra using a relation from Lee et al. ${ }^{24}$ :

$$
r_{r s}=\frac{R_{r s}}{0.52+1.7 * R_{r s}} .
$$

\section{B. Inversion Model}

Semianalytical IOP inversion models ${ }^{9-12}$ are based on three assumptions.

The relation between $r_{\mathrm{rs}}$ and the absorption and backscattering coefficients is known.

The absorption and backscattering coefficients for pure seawater are known.

The spectral shapes of the absorption and backscattering coefficients for in-water constituents are known.

These models often vary in their choice of the $r_{\mathrm{rs}}-\mathrm{IOP}$ relation, the assumed spectral shape of the component IOPs, the wavelength range used in the inversion, and the specifics of the mathematical method of inversion. Below is the description of the specific model used in this paper.

\section{Relation between $r_{r s}$ and Inherent Optical} Properties

The relation between $r_{\mathrm{rs}}(\lambda)$ and the backscattering to absorption coefficients is approximated by ${ }^{25}$

$$
\begin{aligned}
r_{r s}(\lambda) & =\frac{L_{u}\left(\lambda, 0^{-}\right)}{E_{d}\left(\lambda, 0^{-}\right)} \\
& \cong 0.0949 \frac{b_{b}(\lambda)}{a(\lambda)+b_{b}(\lambda)}+0.0794\left(\frac{b_{b}(\lambda)}{a(\lambda)+b_{b}(\lambda)}\right)^{2},
\end{aligned}
$$

where $L_{u}\left(\lambda, 0^{-}\right)$and $E_{d}\left(\lambda, 0^{-}\right)$are the upwelling radiance and downwelling irradiance just beneath the sea surface. The quadratic term is significant $(>4 \%)$ when $b_{b} /\left(a+b_{b}\right)>0.2$, for example, in extremely turbid waters in green wavelengths. 


\section{Assumed Spectral Shapes of the Constituent} Inherent Optical Properties

The total absorption coefficient is partitioned as follows:

$$
a(\lambda)=a_{\mathrm{sw}}(\lambda)+a_{\mathrm{ph}}(\lambda)+a_{\mathrm{CDOM}+\mathrm{NAP}}(\lambda),
$$

where the subscripts sw, ph, and CDOM + NAP designate seawater, phytoplankton and the combined contribution of CDOM and NAP. CDOM and NAP absorption is not separated owing to the similarities in their spectral shapes. ${ }^{9,12}$ The spectral absorption coefficient $a_{\text {sw }}(\lambda)$ for seawater is computed for a given salinity and temperature. ${ }^{26,27}$

The spectral absorption coefficient of phytoplankton, $a_{\mathrm{ph}}(\lambda)$, is parameterized as a function of a size parameter describing the relative contributions of two spectral shapes associated with picophytoplankton and microphytoplankton ${ }^{28}$ :

$$
a_{\mathrm{ph}}(\lambda)=a_{\mathrm{ph}}\left(\lambda_{0}\right)\left[S_{\mathrm{f}} a_{\mathrm{pico}}(\lambda)+\left(1-S_{\mathrm{f}}\right) a_{\text {micro }}(\lambda)\right],
$$

where $a_{\text {pico }}(\lambda)$ and $a_{\text {micro }}(\lambda)$ are the shapes corresponding to the normalized absorption spectral for the smallest and largest cells (values provided in Ciotti et $\left.a l .{ }^{28}\right), \lambda_{0}$ is the reference wavelength, and the size parameter $S_{f}$ varies between zero and one. We chose this parameterization of $a_{\mathrm{ph}}$ based on the success of Ciotti et al. ${ }^{28}$ in fitting spectra of $a_{\mathrm{ph}}$ measured in a wide range of natural waters.

The spectral dependence of the combined absorption by CDOM and NAP is assumed to be

$$
a_{\mathrm{CDOM}+\mathrm{NAP}}(\lambda)=a_{\mathrm{CDOM}+\mathrm{NAP}}\left(\lambda_{0}\right) \exp \left[-S\left(\lambda-\lambda_{0}\right)\right],
$$

where $S$ is the combined CDOM and NAP spectral slope. This function has been found to be an adequate representation of observed CDOM and $\mathrm{NAP}^{29,30}$ with $S$ ranging between 0.008 and 0.023 .

The total backscattering coefficient, $b_{b}(\lambda)$, is approximated by

$$
b_{b}(\lambda)=b_{b s w}(\lambda)+b_{b p}(\lambda)
$$

where the subscripts sw and $\mathrm{p}$ represent water and particulate backscattering, respectively. The spectral backscattering coefficient $b_{b \mathrm{sw}}(\lambda)$ for seawater is computed for a given salinity. ${ }^{31-32}$

The spectral particle backscattering coefficient is assumed to obey

$$
b_{b \mathrm{p}}(\lambda)=b_{b \mathrm{p}}\left(\lambda_{0}\right)\left(\lambda / \lambda_{0}\right)^{-\mathrm{Y}}
$$

consistent with many previous studies, ${ }^{9-12}$ though without in-water validation. ${ }^{33,34}$

To account for variability in space and time of the spectral shapes of the IOP we perform the $r_{\mathrm{rs}}$ inversion allowing the shape parameters $\left(S_{f}\right.$ for phytoplankton absorption, spectral slope $S$ for the combined absorption by CDOM and NAP and spec- tral slope $Y$ for the particulate backscattering) to vary within most of their observed range of variability (0 $\left.\leq S_{f} \leq 1,0.01 \leq S \leq 0.02,0 \leq Y \leq 2\right)$. For each parameter we use 11 different values with equal intervals between their maximum and minimum, resulting in $11^{3}=1331$ different inversion computations for each $r_{\mathrm{rs}}$ spanning all the possible combinations of the shape parameters.

\section{Inversion Technique}

Following Hoge and Lyon, ${ }^{11}$ we define

$$
X \equiv \frac{b_{b}}{a+b_{b}} \rightarrow a+b_{b}\left(1-\frac{1}{X}\right)=0,
$$

where $X$ is computed as the one positive quadratic solution of Eq. (3). Denoting $v \equiv 1-1 / X$ and separating the known seawater IOP, we obtain an equation for the unknown IOPs at each wavelength $\lambda_{i}$, where $i=1, \ldots m$ ( $m$ is the number of wavelengths):

$$
\begin{aligned}
a_{\mathrm{ph}}\left(\lambda_{i}\right)+a_{\mathrm{CDOM}+\mathrm{NAP}}\left(\lambda_{i}\right)+b_{b \mathrm{p}}\left(\lambda_{i}\right) v\left(\lambda_{i}\right)=-\left[a_{\mathrm{sw}}\left(\lambda_{\mathrm{i}}\right)\right. \\
\left.+b_{b s w}\left(\lambda_{i}\right) v\left(\lambda_{i}\right)\right] .
\end{aligned}
$$

With the known right-hand side (RHS) denoted as $h\left(\lambda_{i}\right) \equiv-\left[a_{\mathrm{sw}}\left(\lambda_{i}\right)+b_{b \mathrm{sw}}\left(\lambda_{i}\right) v\left(\lambda_{i}\right)\right]$, Eq. (10) becomes

$$
a_{\mathrm{ph}}\left(\lambda_{i}\right)+a_{\mathrm{CDOM}+\mathrm{NAP}}\left(\lambda_{i}\right)+b_{b \mathrm{p}}\left(\lambda_{i}\right) v\left(\lambda_{i}\right)=h\left(\lambda_{i}\right) .
$$

Equation (11) contains three unknowns for each spectral radiance measurement. The substitution of Eqs. (5)-(7) into (11) yields

$$
\begin{aligned}
& a_{\mathrm{ph}}\left(\lambda_{0}\right)\left[S_{f} a_{\mathrm{pico}}\left(\lambda_{i}\right)+\right.\left.\left(1-S_{f}\right) a_{\text {micro }}\left(\lambda_{i}\right)\right] \\
&+a_{\mathrm{CDOM}+\mathrm{NAP}}\left(\lambda_{0}\right) \exp \left[-S\left(\lambda_{i}-\lambda_{0}\right)\right] \\
&+v\left(\lambda_{i}\right) b_{b \mathrm{p}}\left(\lambda_{0}\right)\left(\lambda_{i} / \lambda_{0}\right)^{-Y}=h\left(\lambda_{i}\right) .
\end{aligned}
$$

Equation (12) contains six unknowns for each wavelength; three amplitudes $a_{\mathrm{ph}}\left(\lambda_{0}\right), a_{\mathrm{CDOM}+\mathrm{NAP}}\left(\lambda_{0}\right), b_{b \mathrm{p}}\left(\lambda_{0}\right)$ and three spectral shape parameters: $S_{f}, S$, and $Y$ (which are not solved for but assumed for each inversion). For each choice of the spectral shape parameters we solve Eq. (12) by matrix inversion to obtain $a_{\mathrm{ph}}\left(\lambda_{0}\right), a_{\mathrm{CDOM}+\mathrm{NAP}}\left(\lambda_{0}\right)$, and $b_{b \mathrm{p}}\left(\lambda_{0}\right)$. A basic difference between our method compared with that of Hoge and Lyon's ${ }^{11}$ is that in the current study we solve Eq. (12) using more wavelengths than unknowns. This makes Eq. (12) an overconstrained system for which the solution is the best solution in a least-squares sense..$^{35}$

\section{Criteria for Selection of Acceptable Solutions}

For each measured $r_{\mathrm{rs}}$, Eq. (12) is solved with a different combination of $S_{f}, S$, and $Y$, resulting in 1331 solutions. We select acceptable solutions by one, requiring that the values of all the amplitudes be positive or zero, and two, requiring that the difference between the $r_{\mathrm{rs}}$ constructed from the solution and the $r_{\mathrm{rs}}$ measured is constrained. Here we chose this constraint to be that the relative difference is less than 


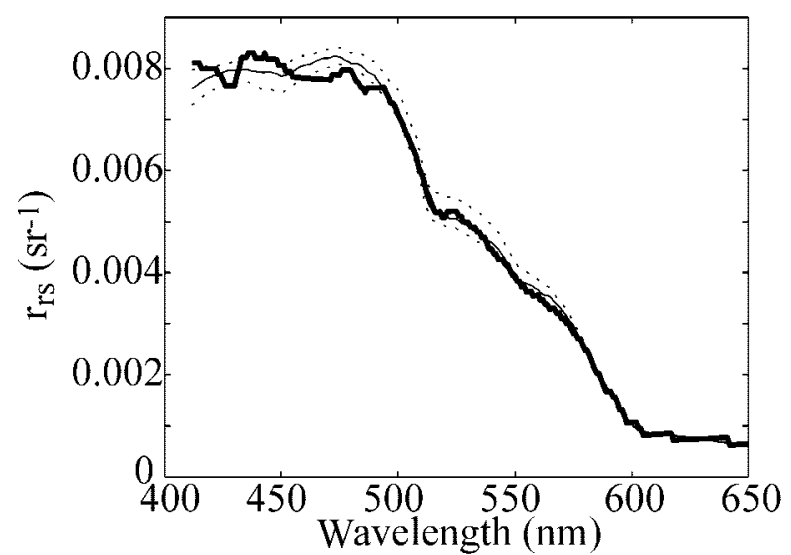

Fig. 1. Comparison of a measured $r_{\mathrm{rs}}(7 / 23 / 2001$, bold curve) with the median values of all the inversion solutions (526) for which the reconstructed $r_{\mathrm{rs}}$ is within $10 \%$ of the measured $r_{\mathrm{rs}}$ at all wavelengths (thin line) and the 5th and 95th percentiles of those solutions (dotted curves).

$10 \%$ at all wavelengths. This constraint is based on an analysis of the following uncertainties:

Uncertainties in the measured $r_{\mathrm{rs}}$ due to instrumental drift. All radiometers were field-calibrated at least every 3 days against a stable light source. The drifts in the measured radiometric quantities were found to be less than $3 \%$ for both the irradiance and the radiance sensors. ${ }^{18}$

Uncertainties caused by the assumed relation between $r_{\mathrm{rs}}$ and IOPs [Eq. (3)]. To evaluate this uncertainty, we input the locally measured IOPs into Eq. (3) and compared with the measured (or Hydrolight derived) $r_{\mathrm{rs}}$ for the field and simulated data set, respectively. The median relative difference for the simulated data set varies from $2.66 \%$ to $9.98 \%$ at all the wavelengths with the difference increasing from blue to red and is less than $8 \%$ for all the IOP bands measured in situ (not shown).

Uncertainties caused by the assumed shape of IOPs. To assess the uncertainties caused by the chosen IOP shapes, we calculate how well the assumed spectral shape fit the input data. The uncertainty of a given IOP shape is quantified by a cost function:

$$
\varepsilon=\frac{1}{N}\left[\sum_{i=1}^{N}\left(\frac{\text { input }- \text { fit }}{\text { input }}\right)^{2}\right]^{1 / 2} .
$$

We find that for $75 \%$ of the $a_{\mathrm{CDOM}+\mathrm{NAP}}$ and all the $b_{b \mathrm{p}}$ data, $\varepsilon<0.01$. For $a_{\mathrm{ph}}$, only $3 \%$ of the data has $\varepsilon$ $<0.01$. However, for $98.2 \%$ of $a_{\mathrm{ph}}$ and $100 \%$ of $a_{\mathrm{CDOM}+\mathrm{NAP}}$ and $b_{b \mathrm{p}}, \varepsilon<0.1$. The median value of the relative difference between fit and observed or assumed $b_{b \mathrm{p}}$ and $a_{\mathrm{CDOM}+\mathrm{NAP}}$ in all wavelengths is less than $4 \%$, whereas it varies from $3 \%$ to $20.7 \%$ for $a_{\mathrm{ph}}$. The largest relative differences in $a_{\mathrm{ph}}$ are in the red part of the spectra $(\lambda>570 \mathrm{~nm})$, where the signal is smallest.

On the basis of the above discussion we choose a criterion for acceptance of an inversion solution if the reconstructed $r_{\text {rs }}$ from the inverted IOPs was within $10 \%$ of the measured $r_{\mathrm{rs}}$ at all wavelengths (see Fig. 2 for a schematic of the algorithm) and had positive IOP amplitudes. Each acceptable solution has a corresponding set of IOP amplitudes $\left[a_{\mathrm{p}] \mathrm{h}}\left(\lambda_{0}\right)\right.$, $\left.a_{\mathrm{CDOM}+\mathrm{NAP}}\left(\lambda_{0}\right), b_{\mathrm{bp}}\left(\lambda_{0}\right)\right]$ and spectral shape parameters $\left(S, S_{f}, Y\right)$. An example of a family of solutions is provided in Fig. 1. For the hundreds of solutions that are within the acceptance criterion, we calculate the median and the 5 and 95 percentiles of the amplitude and shape parameters to provide an estimate of the most likely solution, and to quantify the uncertainty of this solution (see Fig. 3 for an example of a histogram of amplitude distribution for all acceptable solutions). We refer to the $90 \%$ confidence interval as the interval separating the 5 and 95 percentiles (Table 1). In a few cases ( $4 \%$ of the simulated data set and $11 \%$ for the in situ data set) no solution was found that was within the chosen acceptance criterion, which means that no solution was found for which the reconstructed $r_{\mathrm{rs}}$ was within $10 \%$ of the input $r_{\mathrm{rs}}$ at all wavelengths or that the solution found has negative IOP amplitudes. Such cases may occur owing to larger errors resulting from errors in the input $r_{\mathrm{rs}}$, in our inversion model (IOPs $-r_{\mathrm{rs}}$ relation and/or IOP shapes), or in both. These cases are not discussed further.

\section{Results and Discussion}

To compare with other published inversion algorithms and for the sake of brevity, we primarily discuss the inversion results at 410,440 , and $490 \mathrm{~nm}$ for absorption and $550 \mathrm{~nm}$ for backscattering $(555 \mathrm{~nm}$ for the in situ data set). We denote by $a_{\mathrm{p}+\mathrm{CDOM}}$ the sum of particulate and dissolved absorptions, $a_{\mathrm{ph}}$ $+a_{\mathrm{NAP}+\mathrm{CDOM}}$. We refer to the outputs of the inversion model as 'inverted' even when obtaining the shape factors $\left(S_{f}, S\right.$, and $Y$ ) that are assumed in the inversion. We provide a wide range of realistic values for these parameters and provide the statistics of these parameters from all possible solutions, a procedure similar to inversions in which the output is constrained.

\section{A. Simulated Data Set}

Comparing the optical properties between those derived from the inversion and those used to compute $r_{\mathrm{rs}}$ suggests that the inversion scheme is successful (Fig. 4 ). Both the high linear correlations and the low median relative and absolute difference show that the inverted $a_{\mathrm{pg}}(410,440,490)$ and $b_{\mathrm{bp}}(550)$ match their input values well (Table 2). For example, for the entire data set $\left[0.01<a_{p+\mathrm{CDOM}}(440)<3.17 \mathrm{~m}^{-1}\right]$, the correlation coefficient for $a_{\mathrm{p}+\mathrm{CDOM}}(440)$ is 0.99 , and the median relative and absolute differences are $7.75 \%$ and $0.014 \mathrm{~m}^{-1}$, respectively. The correlation coefficient is 0.99 for $b_{b \mathrm{p}}(550), 0.99$ for $a_{\mathrm{NAP}+\mathrm{CDOM}}(440)$, 0.94 for $a_{\mathrm{ph}}(440)$. Absorptions by phytoplankton and by CDOM and NAP are well retrieved. The median of the relative difference is $20 \%$ and $14 \%$ higher com- 


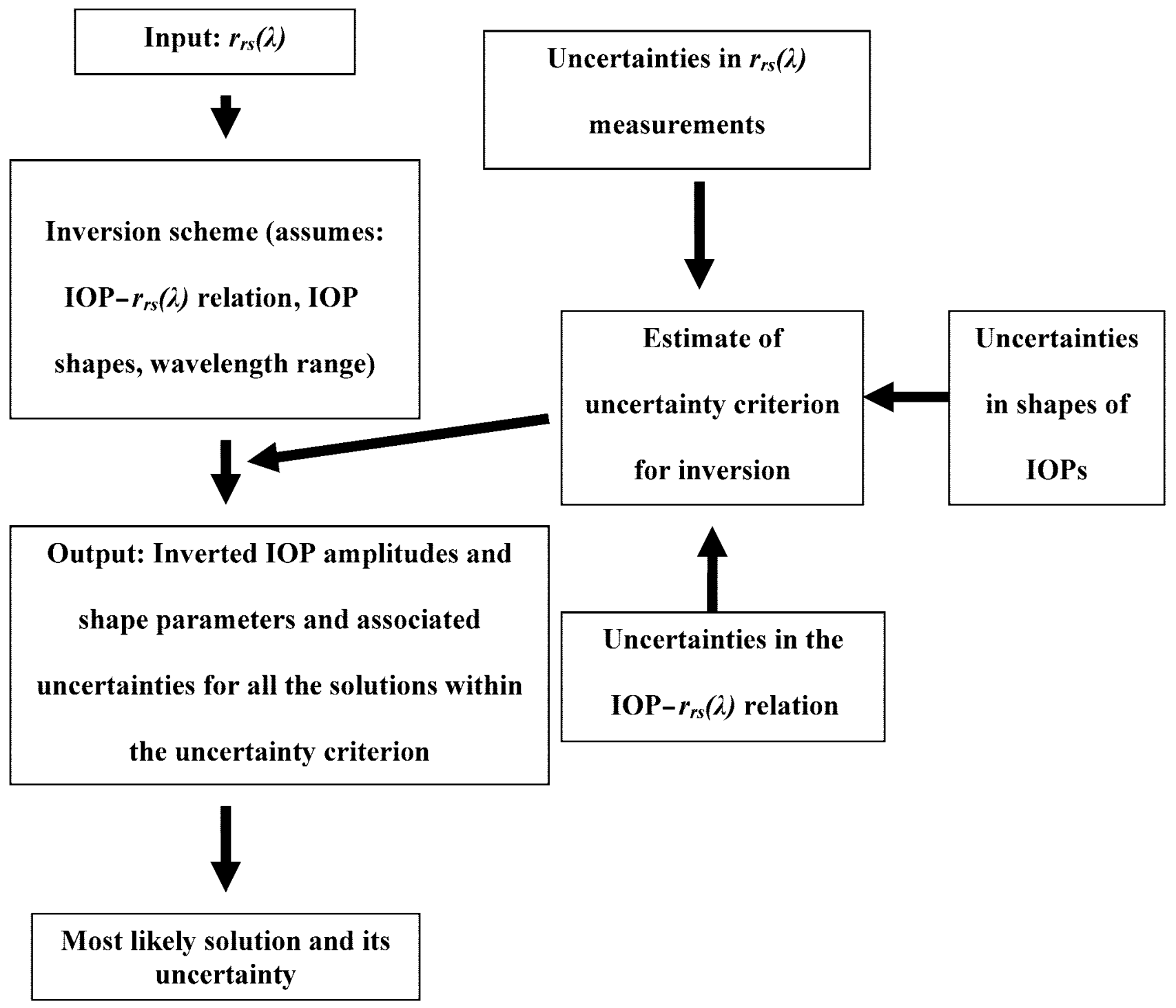

Fig. 2. Schematic flow chart of the inversion scheme and determination of the uncertainty in the inverted parameters.

pared with their total combined absorption. This is likely because both have spectral shapes that generally decrease from blue to red and thus are hard to separate.

The total absorption at $440 \mathrm{~nm}$ is found with fewer than $18 \%$ of the point outside the $90 \%$ confidence intervals, $43 \%$ for backscattering, $10 \%$ for absorption by dissolved materials, and $20 \%$ for absorption by phytoplankton. The percentage of input values covered by the uncertainty range is high except for the backscattering coefficients (Table 2 ).

The relative difference among the inverted $a_{\mathrm{CDOM}+\mathrm{NAP}}, a_{\mathrm{ph}}$, and $b_{b \mathrm{p}}$ and their input values at all wavelengths were also calculated (not shown). The inverted $a_{\mathrm{CDOM}+\mathrm{NAP}}$ and $a_{\mathrm{ph}}$ values fit their input values better in the blue wavelengths; the $a_{\mathrm{CDOM}+\mathrm{NAP}}$ percentage of the relative difference smaller than 10 is nearly $40 \%$ from 400 to $550 \mathrm{~nm}$, and nearly $30 \%$ for $a_{\mathrm{ph}}$ from 400 to $490 \mathrm{~nm}$. That percentage decreases with increasing wavelengths $\left(7.5 \%\right.$ for $a_{\mathrm{CDOM}+\mathrm{NAP}}$ and
$7.9 \%$ for $a_{\mathrm{ph}}$ at $650 \mathrm{~nm}$ ) as signals decrease. For $b_{b \mathrm{p}}$ the inverted results fit best in the middle wavelength at $490-530 \mathrm{~nm}$ (more than $75 \%$ have a relative difference less than $10 \%$ ).

Relative magnitude of uncertainties in absorption by phytoplankton and by CDOM $+\mathrm{NAP}$ and backscattering by particles is relatively uniform as a function of amplitude (Fig. 4), suggesting that the algorithm used here can be used with the same degree of success within waters of high chlorophyll, CDOM, or both as well as in relatively clear waters.

Comparison of spectral shape parameters suggest that they are harder to invert than the amplitudes, in particular because of their limited dynamic range. Both medians of the inverted $S$ and $Y$ values are overestimated [Figs. 5(a) and 5(b)]. The correlation coefficients are high especially given the low dynamic range of these parameters $(r=0.8$ for $S$ and $r=0.9$ for $Y$; the median of the relative difference for $S$ and $Y$ is 0.17 and 0.37 , respectively). 


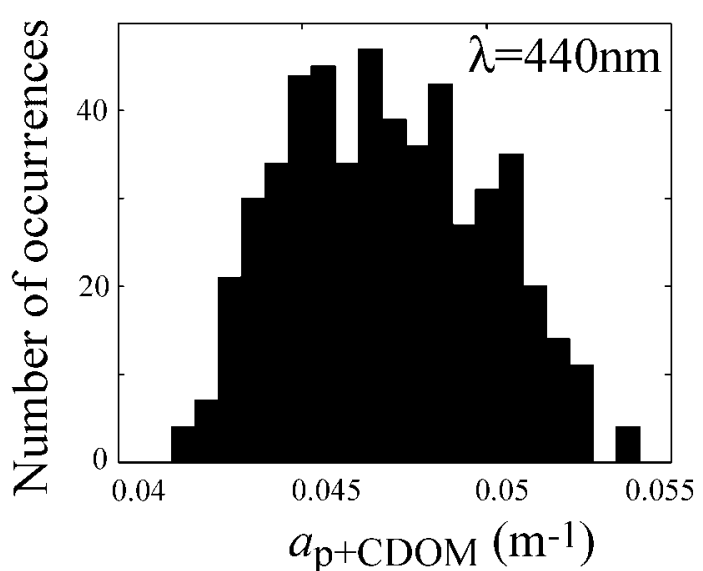

(a)

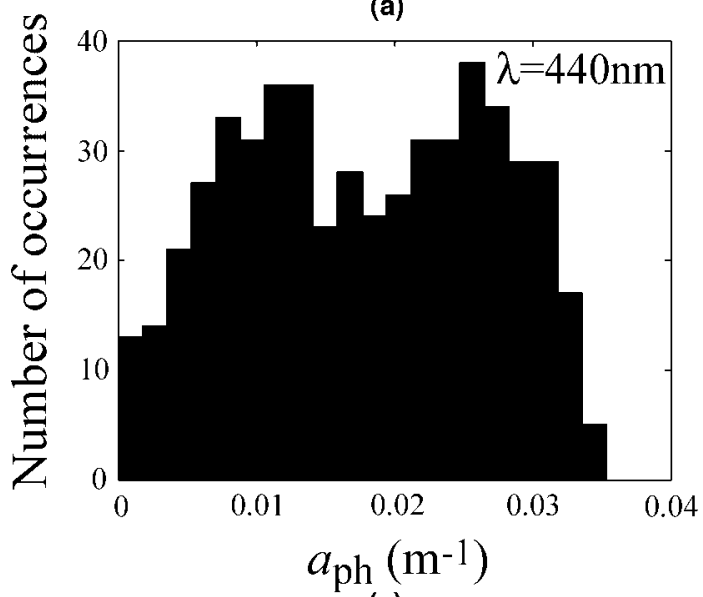

(c)

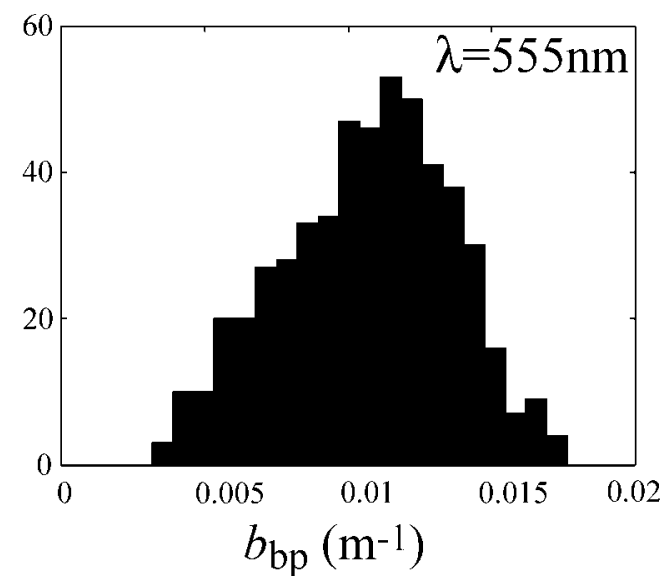

(b)

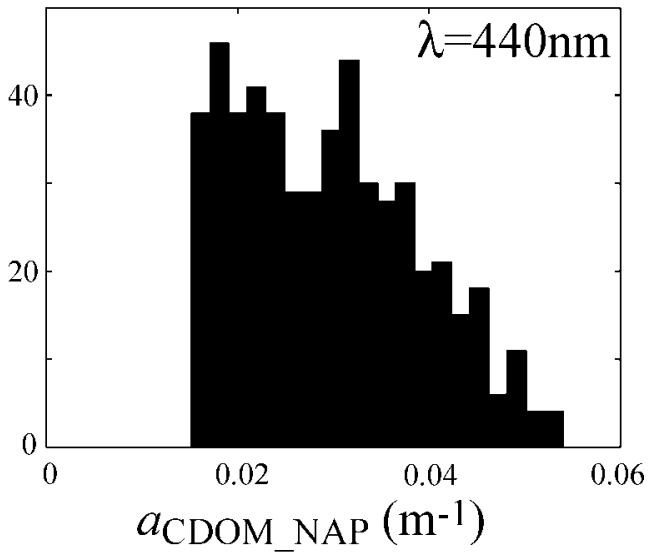

(d)

Fig. 3. Histograms of (a) the inverted total absorption coefficient $\left(a_{\mathrm{p}+\mathrm{CDOM}}=a_{\mathrm{ph}}+a_{\mathrm{CDOM}+\mathrm{NAP}}\right)$ at $440 \mathrm{~nm}$, (b) the particulate backscattering coefficient $\left(b_{\mathrm{bp}}\right)$ at $555 \mathrm{~nm}$, (c) the phytoplankton absorption coefficient $\left(a_{\mathrm{ph}}\right)$ at $440 \mathrm{~nm}$, (d) the CDOM and NAP absorption coefficient $\left(a_{\mathrm{CDOM}+\mathrm{NAP}}\right)$ at $440 \mathrm{~nm}$ for the $r_{\mathrm{rs}}$ presented in Fig. 1.

Inversion uncertainties are high, indicating the inability to obtain these shape parameters with high certainty.

For the phytoplankton absorption, we attempt to correlate the size factor $\left(S_{f}\right)$ with the blue/red ratio of phytoplankton absorption, since size and pigment packaging are correlated. ${ }^{36,37}$ The correlation between the size factor $\left(S_{f}\right)$ for phytoplankton and the ratio of $a_{\mathrm{ph}}$ at 440 to $680 \mathrm{~nm}$ [Fig. 5(c)] is low ( $r$ $=0.18$ ), indicating that the attempt to relate the phytoplankton size factor with the blue-to-red phytoplankton absorption ratio is not successful. Given that the input $a_{\mathrm{ph}}$ was not well represented by the model $a_{\mathrm{ph}}$ (see Subsection 2.C) it may not be surprising that the spectral shape is not retrieved well.

Table 1. Comparison between the Inverted and the Input IOP Values of the Simulated Data Set

\begin{tabular}{|c|c|c|c|c|c|c|c|}
\hline $\begin{array}{l}\text { Compared } \\
\text { Quantity }\end{array}$ & $\begin{array}{l}\text { Dynamic Range } \\
\qquad\left(\mathrm{m}^{-1}\right)\end{array}$ & $\begin{array}{c}\text { Median } \\
\text { Relative } \\
\text { Difference } \\
(\%)\end{array}$ & $\begin{array}{c}95 \% \\
\text { Relative } \\
\text { Difference } \\
(\%)\end{array}$ & $\begin{array}{c}\text { Median } \\
\text { Absolute } \\
\text { Difference } \\
\left(\mathrm{m}^{-1}\right)\end{array}$ & $\begin{array}{c}95 \% \\
\text { Absolute } \\
\text { Difference } \\
\left(\mathrm{m}^{-1}\right)\end{array}$ & $R$ & $\begin{array}{l}\text { Percentage of } \\
\text { the Data Inside } \\
90 \% \text { Confidence } \\
\text { Interval }\end{array}$ \\
\hline$a_{\mathrm{p}}+\operatorname{CDOM}(410)$ & $0.0095 \sim 4.53$ & 8.95 & 37.9 & 0.0194 & 0.671 & 0.988 & 82.9 \\
\hline$a_{\mathrm{p}}+\operatorname{CDOM}(440)$ & $0.0095 \sim 3.17$ & 7.75 & 30.9 & 0.0138 & 0.438 & 0.989 & 83.1 \\
\hline$a_{\mathrm{p}}+\operatorname{CDOM}(490)$ & $0.0051 \sim 1.92$ & 6.78 & 21.8 & 0.0047 & 0.157 & 0.992 & 85.8 \\
\hline$b_{b \mathrm{p}}(550)$ & $0.00052 \sim 0.13$ & 7.55 & 15.9 & 0.0006 & 0.0082 & 0.993 & 56.8 \\
\hline$a_{\mathrm{ph}}(410)$ & $0.0034 \sim 0.42$ & 20.5 & 63.4 & 0.0068 & 0.0977 & 0.911 & 84.8 \\
\hline$a_{\mathrm{ph}}(440)$ & $0.0056 \sim 0.42$ & 19.8 & 61.2 & 0.0092 & 0.134 & 0.937 & 80.6 \\
\hline$a_{\mathrm{ph}}(490)$ & $0.0031 \sim 0.32$ & 22.1 & 66.4 & 0.0064 & 0.0829 & 0.946 & 87.7 \\
\hline$a_{\mathrm{CDOM}+\mathrm{NAP}}(410)$ & $0.0060 \sim 4.17$ & 14.5 & 43.9 & 0.0218 & 0.628 & 0.988 & 81.8 \\
\hline$a_{\mathrm{CDOM}+\mathrm{NAP}}(440)$ & $0.0039 \sim 2.75$ & 14.4 & 40.1 & 0.0119 & 0.330 & 0.99 & 90.0 \\
\hline$a_{\mathrm{CDOM}+\mathrm{NAP}}(490)$ & $0.0012 \sim 1.63$ & 14.7 & 61.1 & 0.0077 & 0.0939 & 0.991 & 89.1 \\
\hline
\end{tabular}



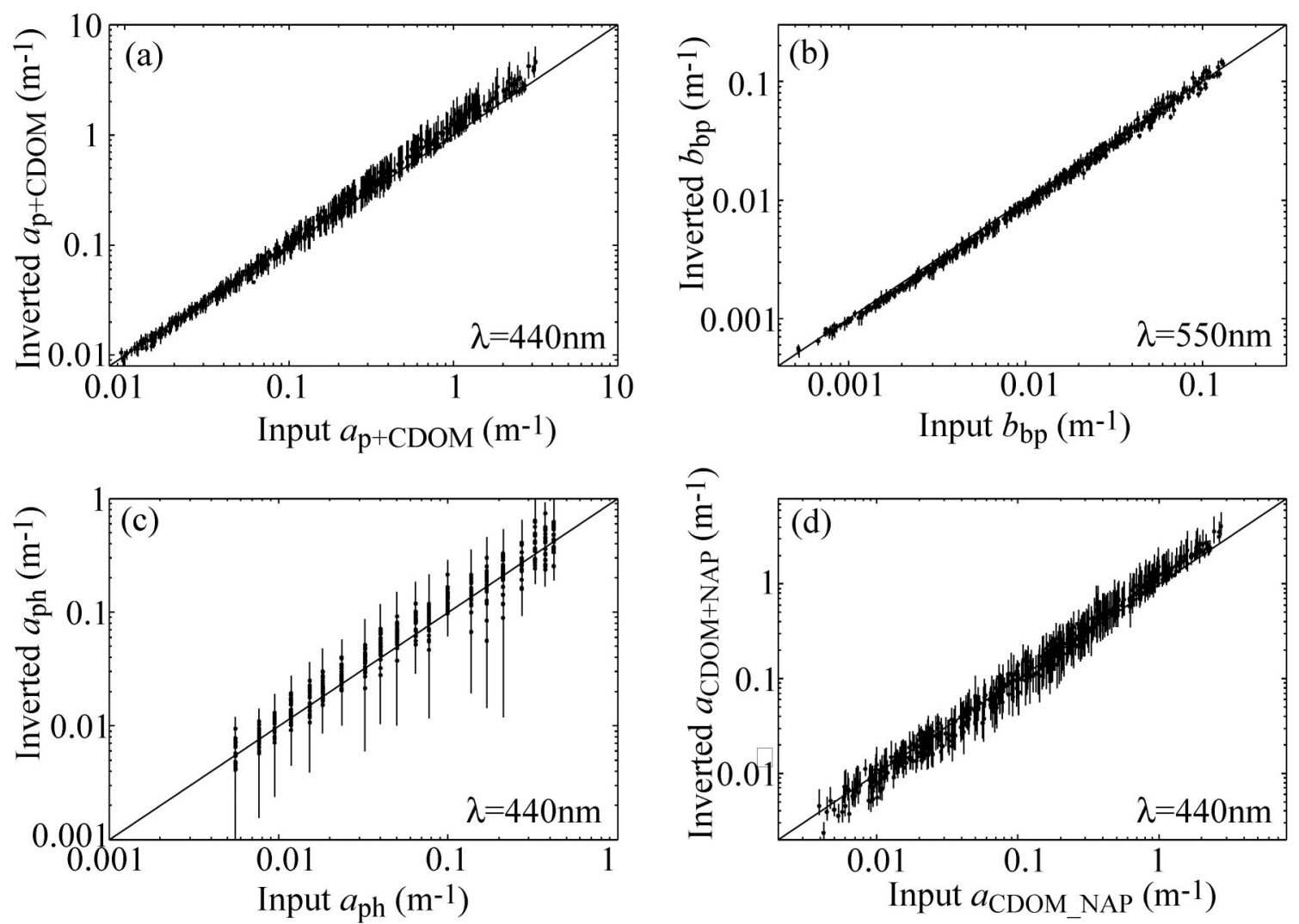

Fig. 4. Comparison of the inverted values of (a) $a_{p+\mathrm{CDOM}}(440)$, (b) $b_{\mathrm{bp}}(550)$, (c) $a_{\mathrm{ph}}(440)$, (d) $a_{\mathrm{CDOM}+\mathrm{NAP}}(440)$ relative to the input values $(x$ axis) for the simulated data set. Dots denote the median inverted values, whereas the lines denote the $90 \%$ confidence interval.

\section{B. Field Data}

Comparison of retrieved optical properties with those measured in situ at 410,440 , and $490 \mathrm{~nm}$ indicate good agreement (Fig. 6). Over the entire data set $\left[0.049<a_{\mathrm{p}+\mathrm{CDOM}}(440)<0.828 \mathrm{~m}^{-1}, 0.001\right.$ $<b_{b \mathrm{p}}(555)<0.0343 \mathrm{~m}^{-1}$ ], the correlation coefficient for $a_{\mathrm{p}+\mathrm{CDOM}}(440)$ is $r=0.94$ and the median relative and absolute differences are $12 \%$ and $0.0488 \mathrm{~m}^{-1}$, respectively. The correlation coefficient of $b_{b \mathrm{p}}(555)$ is 0.98 , and the median relative and absolute differences are $23 \%$ and $0.0026 \mathrm{~m}^{-1}$, respectively. Note that measured IOPs are not error free (indicated by horizontal lines in Fig. 6). The particulate and dissolved absorption coefficient $\left(a_{\mathrm{p}+\mathrm{CDOM}}\right)$ at $440 \mathrm{~nm}$ is found with less than $15 \%$ of the point outside the $90 \%$ confidence interval, $65 \%$ for backscattering coefficient $\left(b_{b \mathrm{p}}\right)$ at $555 \mathrm{~nm}$ (Fig. 6).

In the in situ data set, the combined absorption by CDOM and NAP is unavailable. Only CDOM absorption was measured, so we compare $a_{\mathrm{CDOM}+\mathrm{NAP}}$ with $a_{\mathrm{CDOM}}[$ [Fig. 6(c)]. The linear correlation coefficient for $a_{\mathrm{CDOM}+\mathrm{NAP}}(440)$ and $a_{\mathrm{CDOM}}(440)$ is $r=0.86$, and the median relative and absolute differences are $18 \%$ and $0.0368 \mathrm{~m}^{-1}$, respectively. Absorption by CDOM and NAP at $440 \mathrm{~nm}$ is found with less than $7 \%$ of the points outside the $90 \%$ confidence interval. Not surprisingly, $73 \%$ of inverted $a_{\mathrm{CDOM}+\mathrm{NAP}}$ values (averaged over the three wavelengths) are higher than the mea-

Table 2. Comparison between the Inverted and the Input IOP Values of the In Situ Data Set

\begin{tabular}{lcccccc}
\hline $\begin{array}{c}\text { Compared } \\
\text { Quantity Inversion/ } \\
\text { Observation }\end{array}$ & $\begin{array}{c}\text { Median } \\
\text { Relative } \\
\text { Range }\left(\mathrm{m}^{-1}\right)\end{array}$ & $\begin{array}{c}\text { 95\% } \\
(\%)\end{array}$ & $\begin{array}{c}\text { Relative } \\
\text { Difference } \\
(\%)\end{array}$ & $\begin{array}{c}\text { Median } \\
\text { Absolute } \\
\text { Difference } \\
\left(\mathrm{m}^{-1}\right)\end{array}$ & $\begin{array}{c}\text { 95\% } \\
\text { Absolute } \\
\text { Difference } \\
\left(\mathrm{m}^{-1}\right)\end{array}$ & $\begin{array}{c}\text { Percentage of } \\
\text { the Point Inside } \\
90 \% \text { Confidence } \\
\text { Interval }\end{array}$ \\
\hline$a_{\mathrm{p}}+\mathrm{CDOM}(412)$ & $0.047 \sim 1.01$ & 13.3 & 32.8 & 0.0725 & 0.266 & 0.909 \\
$a_{\mathrm{p}}+\mathrm{CDOM}(440)$ & $0.049 \sim 0.83$ & 11.7 & 27.9 & 0.0488 & 0.175 & 0.942 \\
$a_{\mathrm{p}}+\mathrm{CDOM}(488)$ & $0.025 \sim 0.49$ & 13.1 & 27.6 & 0.0347 & 0.107 & 0.958 \\
$b_{b \mathrm{p}}(555)$ & $0.001 \sim 0.034$ & 22.8 & 36.6 & 0.0026 & 0.0085 & 0.975 \\
$a_{\mathrm{ph}}(676)$ & $0.0041 \sim 0.15$ & 14.7 & 145 & 0.0124 & 0.0478 & 0.901 \\
$a_{\mathrm{dg}}(412) / a_{g}(412)$ & $0.029 \sim 0.42$ & 17.6 & 55.3 & 0.0573 & 0.208 & 0.934 \\
$a_{\mathrm{dg}}(440) / a_{g}(440)$ & $0.023 \sim 0.42$ & 17.8 & 48.2 & 0.0368 & 0.133 & 0.855 \\
$a_{\mathrm{dg}}(488) / a_{g}(488)$ & $0.0095 \sim 0.14$ & 27.9 & 63.4 & 0.0204 & 0.786 & 0.923 \\
\hline
\end{tabular}




\begin{tabular}{lll}
\hline \multicolumn{1}{c}{ Variable } & \multicolumn{1}{c}{ Units } & \multicolumn{1}{c}{ Definition } \\
\hline$a$ & $\mathrm{~m}^{-1}$ & Total absorption coefficient: $a_{\mathrm{sw}}+a_{\mathrm{p}+\mathrm{CDOM}}$ \\
$a_{\mathrm{sw}}$ & $\mathrm{m}^{-1}$ & Ocean water absorption coefficient \\
$a_{\mathrm{p}+\mathrm{CDOM}}$ & $\mathrm{m}^{-1}$ & Particulate (phytoplankton $+\mathrm{NAP})$ and CDOM absorption coefficient \\
$a_{\mathrm{CDOM}+\mathrm{NAP}}$ & $\mathrm{m}^{-1}$ & CDOM + NAP absorption coefficient \\
$a_{\mathrm{ph}}$ & $\mathrm{m}^{-1}$ & Phytoplankton pigments absorption coefficient \\
$b_{b}$ & $\mathrm{~m}^{-1}$ & Total backscattering coefficient: $b_{b \mathrm{sw}}+b_{b \mathrm{p}}$ \\
$b_{\mathrm{bsw}}$ & $\mathrm{m}^{-1}$ & Ocean water backscattering coefficient \\
$b_{b \mathrm{p}}$ & $\mathrm{m}^{-1}$ & Particulate backscattering \\
$\mathrm{S}$ & $\mathrm{nm}^{-1}$ & Combined CDOM and NAP spectral slope \\
$S_{\mathrm{f}}$ & & Phytoplankton size parameter \\
$\mathrm{Y}$ & & Particulate backscattering spectral slope \\
$a_{\mathrm{pico}}$ & $\mathrm{m}^{2} \mathrm{mg}^{-1}$ & Phytoplankton absorption spectral shapes for the smallest cells \\
$a_{\mathrm{micro}}$ & $\mathrm{m}^{2} \mathrm{mg}^{-1}$ & Phytoplankton absorption spectral shapes for the largest cells \\
$R_{\mathrm{rs}}$ & $\mathrm{sr}^{-1}$ & Above-surface remote-sensing reflectance spectra \\
$r_{\mathrm{rs}}$ & $\mathrm{sr}^{-1}$ & Below-surface remote-sensing reflectance spectra \\
$L_{u}\left(0^{-} / 0.66\right)$ & $\mathrm{Wm}^{-2} \mathrm{sr}^{-1}$ & Upwelling radiance just beneath or at 66 cm below the sea surface \\
$E_{d}\left(0^{-/+}\right)$ & $\mathrm{Wm}^{-2}$ & Downwelling irradiance just below or just above the sea surface. \\
$t$ & & Radiance transmittance of the surface \\
$n$ & & Real index of refraction of water \\
$\theta_{\mathrm{s}}$ & & Polar direction of the Sun's refracted beam in water \\
\hline
\end{tabular}

*Blank entries denote dimensionless quantities.
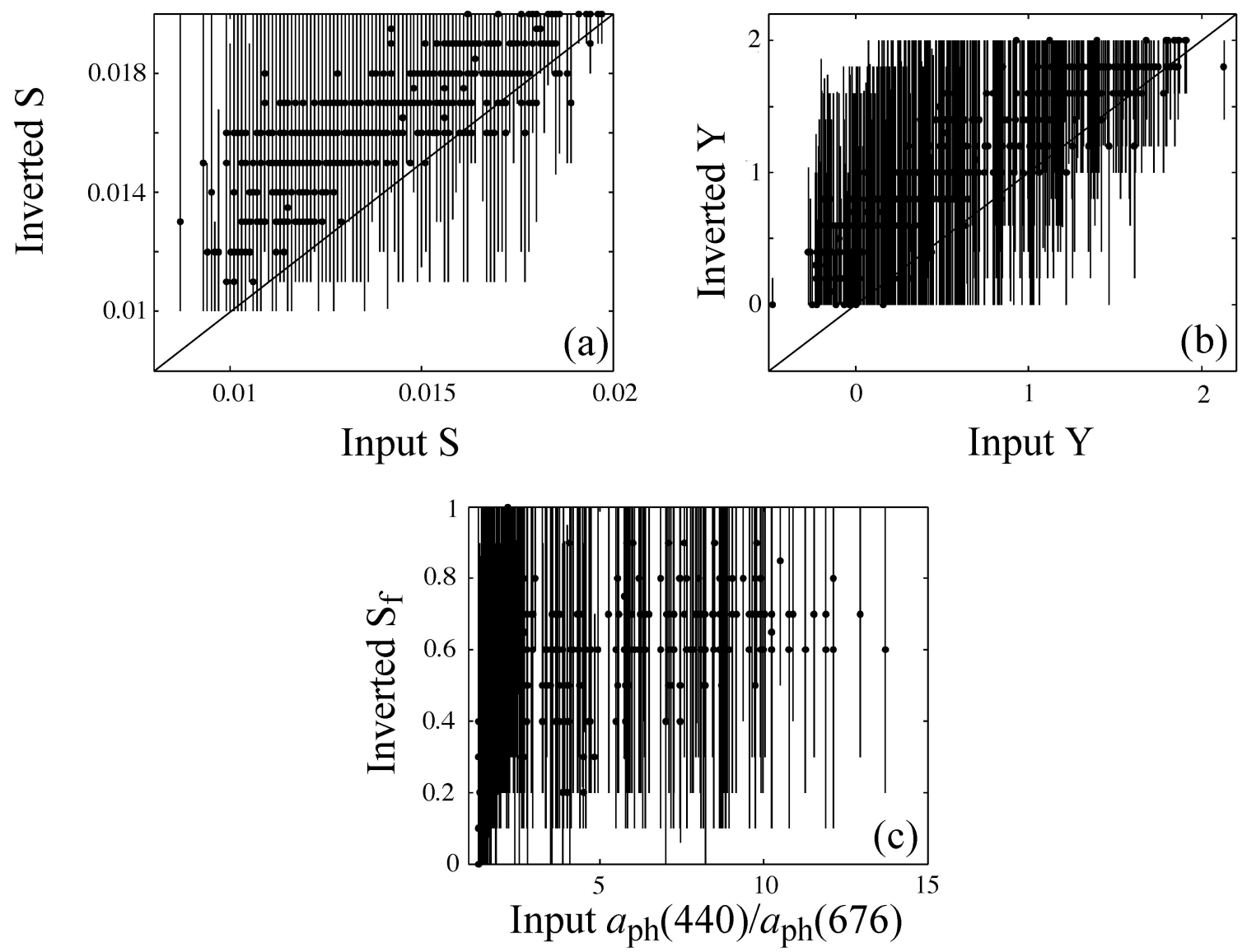

Fig. 5. Comparison (a) between the directly calculated and the inverted spectral slope of CDOM+NAP $(S)$, (b) of the spectral slope of particle backscattering, (c) between the size parameter $\left(S_{f}\right)$ for phytoplankton and the ratio of $a_{\mathrm{ph}}$ at 440 to $680 \mathrm{~nm}$ of the input phytoplankton spectrum. Dots denote the median inverted values, whereas the lines denote the $90 \%$ confidence interval in the inverted parameters (based on the statistics of all acceptable solutions). 

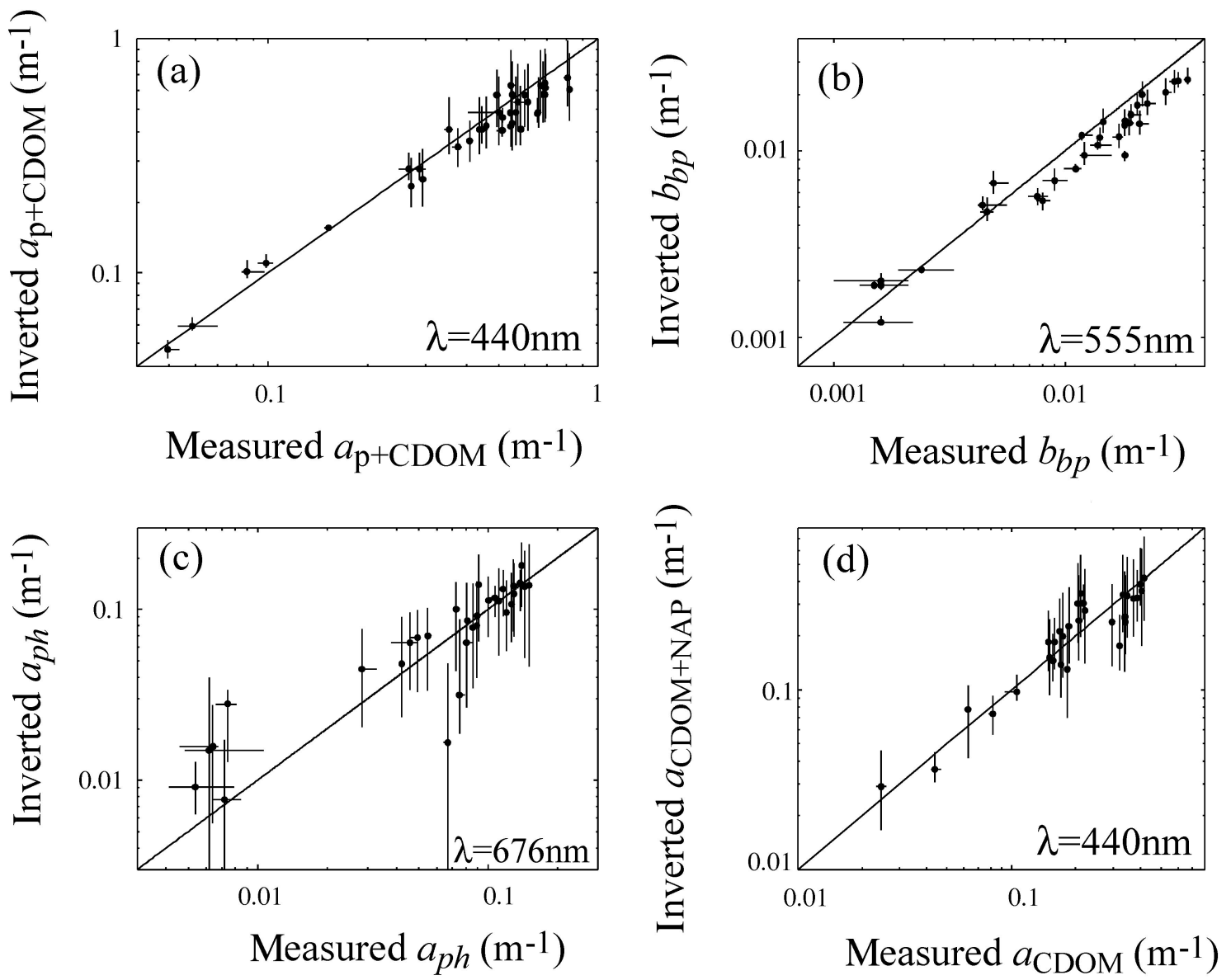

Fig. 6. Comparison for the in situ data set between (a) the inverted $a_{\mathrm{p}+\mathrm{CDOM}}(440)$ versus ac -9 measured, $a_{\mathrm{p}+\mathrm{CDOM}}(440)$, (b) the inverted $b_{b \mathrm{p}}(555)$ versus HS6-measured $b_{b \mathrm{p}}(555)$, (c) the inverted $a_{\mathrm{ph}}(676)$ versus $a_{\mathrm{ph}}(676)$ derived from ac-9 measurements, (d) the inverted $a_{\mathrm{CDOM}+\mathrm{NAP}}(440)$ versus ac-9-measured $a_{\mathrm{CDOM}}(440)$. Dots denote the median values, whereas the vertical lines denote the $90 \%$ confidence interval in the inverted parameters. Horizontal lines denote the distance between maximum and minimum values of the in situ measured parameters (when larger than the size of the dot).

sured $a_{\mathrm{CDOM}}$ values, as the in situ measurement does not include absorption by NAP.

The field data set does not contain phytoplankton absorption. We compute the phytoplankton absorption at $676 \mathrm{~nm}$ from the phytoplankton absorption line height at $676 \mathrm{~nm}^{38}$ :

$$
a_{\mathrm{ph}}(676)=a_{\mathrm{p}+C D O M}(676)-0.6 a_{\mathrm{p}+C D O M}(650) .
$$

This procedure is designed to remove the contribution of NAP $+\mathrm{CDOM}$ absorption from $a_{\mathrm{p}+C D O M}(676)$.

The linear correlation of $a_{\mathrm{ph}}(676)$ is high; $R=0.9$, and the median relative and absolute difference are $15 \%$ and $0.0124 \mathrm{~m}^{-1}$, respectively [(Fig. 6(d)]. Absorption by phytoplankton at $676 \mathrm{~nm}$ is found with less than $13 \%$ of the points outside the $90 \%$ confidence interval.

Because we did not have information on the size of the underlying phytoplankton during the field measurements, we attempted to correlate the phytoplankton size factor $S_{f}$ with the slope of the particulate beam attenuation for the in situ data. The slope of particulate beam attenuation was found to correlate with the particle size distribution. ${ }^{39}$ The low linear correlation $(R=0.08)$ indicate that the relation between the size factor for phytoplankton and the slope of the particulate beam attenuation is not significant.

Comparison of the inverted spectral slope of $\mathrm{CDOM}+\mathrm{NAP}(S)$ and particulate backscattering $(Y)$ with the calculated values for the measured spectra yield $R=0.2$ for $S$ and $R=0.09$ for $Y$ with large inversion uncertainties. Thus, while the amplitudes of the IOPs are retrieved well and within the computed uncertainties, the spectral shape parameters are not retrieved within a useful range (Fig. 7).

\section{Conclusions}

A novel method to provide uncertainties in inverted parameters obtained from remotely sensed reflectance data was developed. This method was applied to a specific semianalytical inversion scheme to retrieve the particulate backscattering coefficients and the absorption coefficients of phytoplankton pigments and CDOM and NAP, as well as the uncertainties in the inverted parameters. This approach to compute uncertainties is general and can be adapted to all current semiempirical inversion schemes. Such 

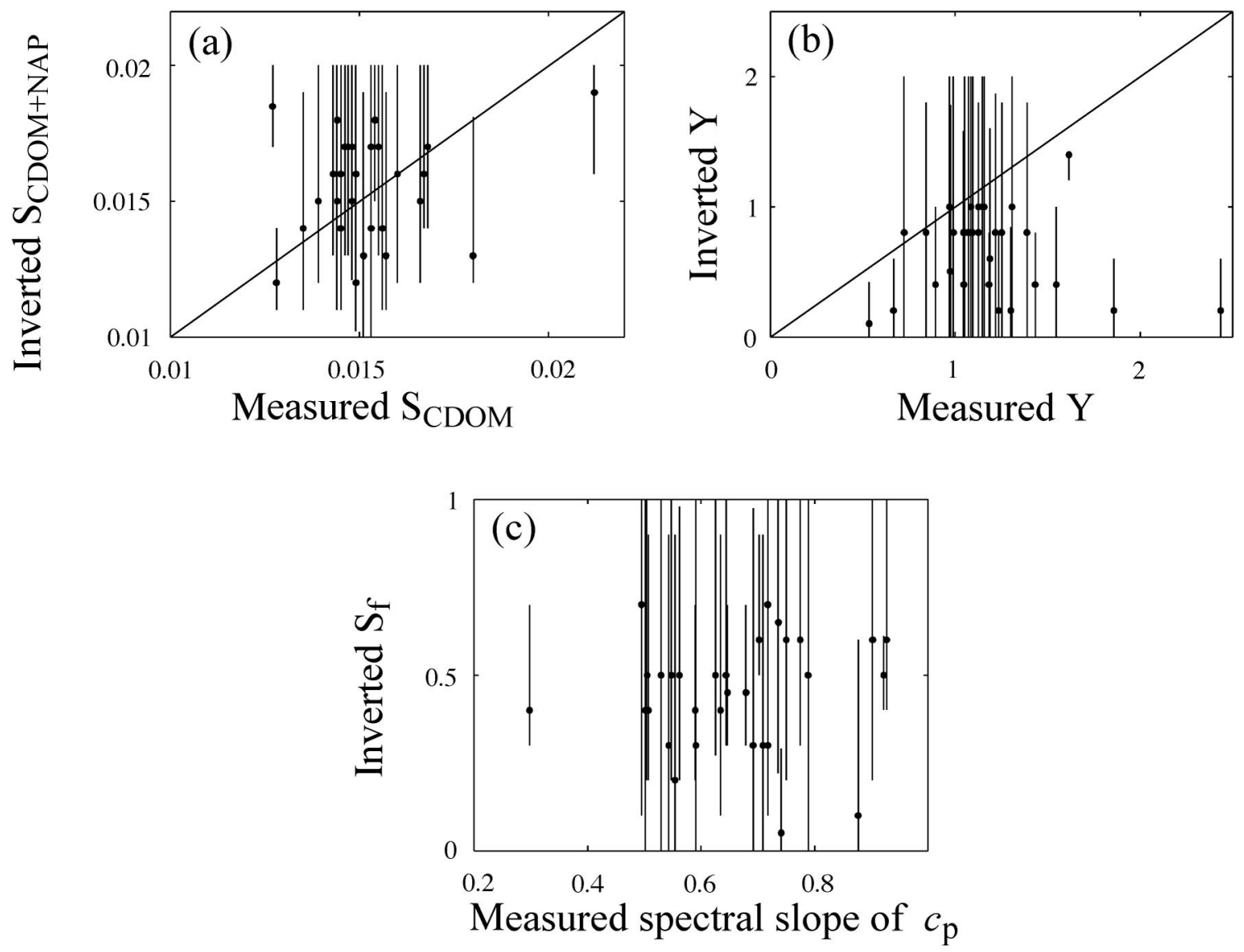

Fig. 7. (a) Comparison between the inverted spectral slope of CDOM and NAP and the calculated spectral slop of CDOM measured with the ac-9. (b) Comparison between the inverted spectral slope of particulate backscattering and the calculated spectral slope of particulate backscattering $(Y)$ based on measurements with the HS-6. (c) Comparison between the phytoplankton size factor $S_{f}$ and the slope of the particulate beam attenuation for the in situ data. Uncertainties in measured spectral slopes were less than 0.002 for $S$, 0.1 for $Y$, and 0.1 for the slope of $c_{\mathrm{p}}$. Dots denote the median values, whereas the lines denote the $90 \%$ confidence interval.

adaptation will require a discretization of all shape factors so that a linear system can be solved as presented above.

To test the performance of the algorithm, we applied it to both a simulated and a field data set of hyperspectral remotely sensed reflectance $\left(r_{\mathrm{rs}}\right)$. The low median absolute differences of inverted IOPs and high linear correlation with input or measured IOPs suggest that the specific scheme used here can extract the absorption and backscattering from $r_{\mathrm{rs}}$ successfully in both the simulated and the field data sets.

We concentrated on quantifying uncertainties in the retrieved IOPs because of uncertainties in the values of the radiance measurement, uncertainties in the spectral shape of IOPs and uncertainties in the relation between the $r_{\mathrm{rs}}$ and the IOPs. Using both a field and simulated data set, we found that the specific inversion scheme to quantify uncertainties works well: at least $80 \%$ of the absorption amplitudes were within the $90 \%$ confidence intervals. Separating the component of absorption we find that more of the measurements (or inputs) are outside the uncertainty bound.

The percentage of the backscattering coefficient within the $90 \%$ confidence interval was significantly lower $(\sim 50 \%)$ compared with the absorption coefficients. This lower percentage may be because backscattering is not necessarily well described by a power law as a function of wavelength, in particular in waters dominated by phytoplankton. ${ }^{33,40}$

Little is known about natural variability of the backscattering spectral slope, $Y{ }^{33,34}$ Comparisons between the inverted and the directly calculated spectral slopes of particle backscattering $(Y)$ based on the simulated data set suggest that the inversion algorithm can provide a reliable $Y$ prediction. The comparison of spectral slopes for the field data, however, does not work well, as predicted uncertainties are too large to be of practical use.

Attempts to link a size factor $\left(S_{f}\right)$ for phytoplankton to a measure of pigment packaging $\left[a_{\mathrm{ph}}(676) /\right.$ $\left.a_{\mathrm{ph}}(440)\right]$ or the spectral slope of the particulate beam attenuation were not successful. Inversion uncertainties are large and correlations with related parameters from both simulated and in situ data are weak. This failure may be due to our choice of a model for $a_{\mathrm{ph}}$ [Eq. 5] not matching well the underlying phytoplankton absorption and the sensitivity of $S_{f}$ to the uncertainties in our inversion input and procedure, as highlighted by the large uncertainties. For the in situ 
data set, the lack of correlation with the spectrum of particulate attenuation may be an indication that phytoplankton did not dominate attenuation in these data (though other evidence, namely, the value of the particulate backscattering ratio, ${ }^{41}$ suggests they did).

Possible improvements of the specific inversion scheme used here may be the use of a library of phytoplankton absorption rather than an analytical expression, ${ }^{40}$ addition of wavelengths in the infrared to better constrain $b_{\mathrm{bp}},{ }^{42}$ and inclusion of inelastic scattering effects on $r_{\mathrm{rs}}{ }^{43}$

The scheme to obtain the uncertainties presented here relies on solving a linear problem approximately 1000 times for each $r_{\mathrm{rs}}$ spectra. Given advances in linear computation techniques, this should not pose a problem for applications with large data sets. It could also be used, for example, on a subset of a satellite image to provide estimates of the uncertainties while taking into account the known spatial decorrelation scales. In addition, the linear scheme used here always finds the one best solution (in a linear leastsquares sense ${ }^{35}$ ), which is not guaranteed with nonlinear inversion schemes used currently in most semianalytical models. ${ }^{9,10,12,44}$ In the nonlinear inversion case there is no guarantee of finding the global minimum in the search for a solution, but rather the local minimum near a given initial guess. ${ }^{35}$ This local minimum may be the global minimum sought, yet there is no guarantee that it is.

The minimum number of required wavelengths is three, given the nature of the linear problem we are solving (solving for three amplitudes when three shape parameters are assumed). Additional wavelengths provide additional constraints, reducing the uncertainties on both amplitudes and spectral shapes. It should therefore be possible to use the approach outlined here with current multispectral ocean color satellites. In that case, uncertainties in $r_{\mathrm{rs}}$ due to atmospheric correction should be added to the uncertainty budgets.

This research has been funded by the environment optics program of the Office of Naval Research as part of HyCODE (Hyperspectral Coupled Ocean Dynamics Experiments). Discussions with M. J. Perry, A. Thomas, and Z. P. Lee during the course of this research are greatly appreciated. We thank S. Pegau for his help collecting the field data set and Z. P. Lee for his simulated data set. We thank S. Maritorena and an anonymous reviewer for their thoughtful and helpful reviews of an earlier version of this manuscript.

\section{References}

1. R. W. Preisendorfer, Hydrologic Optics, (U. S. Department of Commerce, U.S. GPO, Washington, D.C.,1976).

2. C. D. Mobley, Light and Water. Radiative Transfer in Natural Waters (Academic, San Diego, Calif., 1994).

3. H. R. Gordon, O. B. Brown, and M. M. Jacobs, "Computed relationships between the inherent and apparent optical properties of a flat homogeneous ocean," Appl. Opt. 14, 417-427 (1975).
4. A. Morel and L. Prieur, "Analysis of variations in ocean color," Limnol. Ocean. 22, 709-722 (1977).

5. A. Morel, "Available, usable and stored radiant energy in relation to marine photosynthesis," Deep-Sea Res. 25, 673-688 (1978).

6. D. Stramski, R. A. Reynolds, M. Kahru, and B. G. Mitchell, "Estimation of particulate organic carbon in the ocean from satellite remote sensing," Science 285, 239-242 (1999).

7. D. A. Siegel, S. Maritorena, D. A. Hansell, and M. LorenziKayser, "Global distribution and dynamics of colored dissolved and detrital organic materials," J. Geophys. Res. 107, 10.1029/2001JC000965 (2002).

8. M. J. Behrenfeld, E. Boss, D. A. Siegel, and D. M. Shea, "Carbon-based ocean productivity and phytoplankton physiology from space” Global Biogeochem. Cycles 19, GB1006, doi: 10.1029/2004GB002299 (2005).

9. C. S. Roesler and M. J. Perry, "In situ phytoplankton absorption, fluorescence emission, and particulate backscattering spectra determined from reflectance," J. Geophys. Res. 100, 13279-13294 (1995).

10. Z. P. Lee, K. L. Carder, T. G. Peacock, C. O. Davis, and J. L. Mueller, "Method to derive ocean absorption coefficients from remote-sensing reflectance," Appl. Opt. 35, 453-462 (1996).

11. F. E. Hoge and P. E. Lyon, "Satellite retrieval of inherent optical properties by linear matrix inversion of oceanic radiance models: an analysis of model and radiance measurement errors," J. Geophys. Res. 101, 16631-16648 (1996).

12. A. H. Garver and D. A. Siegel, "Inherent optical property inversion of ocean color spectra and its biogeochemical interpretation. 1. Time series from the Sargasso Sea," J. Geophys, Res. 102, 18607-18625 (1997).

13. K. L. Carder, F. R. Chen, Z. P. Lee, S. K. Hawes, and D. Kamykowski, "Semianalytic Moderate-Resolution Imaging Spectrometer algorithms for chlorophyll-a and absorption with bio-optical domains based on nitrate-depletion temperatures," J. Geophys, Res. 104, 5403-5421 (1999).

14. S. Maritorena and D. A. Siegel, "Consistent merging of satellite ocean color data sets using a bio-optical model," Remote Sens. Environ. 94, 429-440 (2005).

15. Z. P. Lee, http://www.ioccg.org/groups/lee_data.pdf (2004).

16. Z. P. Lee, http://www.ioccg.org/groups/lee.html (2004).

17. Z. P. Lee, http://www.ioccg.org/groups/OCAG_data.html (2204).

18. G. C. Chang, T. D. Dickey, C. D. Mobley, E. Boss, and W. S. Pegau, "Toward closure of upwelling radiance in coastal waters," Appl. Opt. 42, 1574-1582 (2003).

19. C. D. Mobley, L. K. Sundman, and E. Boss, "Phase function effects on oceanic light fields," Appl. Opt. 41, 1035-1050 (2002).

20. A. H. Barnard, W. S. Pegau, and J. R. V. Zaneveld, "Global relationships of the inherent optical properties of the oceans," J. Geophys, Res. 103, 24955-24968 (1998).

21. J. L. Mueller, G. S. Fargion, and C. R. McClain, eds., Ocean Optics Protocols for Satellite Ocean Color Sensor Validation, Rev. 4, in Vol. IV: Inherent Optical Properties: Instruments, Characterizations, Field Measurements and Data Analysis Protocols, TM-2003-211621/Rev4-Vol.IV (NASA, 2003), http: //www.wetlabs.com/appnotes/Vol\%201V\%20v4\%20final.pdf.

22. H. R. Gordon and O. B. Brown, "The diffuse reflectance of the ocean: some effects of vertical structure," Appl. Opt. 14, 28922895 (1975).

23. C. D. Mobley, "Notes on converting TSRB data to remotesensing reflectance," Sequoia Scientific, Inc., Bellevue, Wash. (personal communication, 2000).

24. Z. P. Lee, K. L. Carder, and R. A. Arnone, "Deriving inherent optical properties from water color: a multiband quasianalytical algorithm for optically deep waters," Appl. Opt. 41, 5755-5772 (2002).

25. H. R. Gordon, O. B. Brown, R. H. Evans, J. W. Brown, R. C. 
Smith, K. S. Baker, and D. K. Clark, "A semianalytic radiance model of ocean color," J. Geophys, Res. 93, 10909-10924 (1988).

26. R. M. Pope and E. S. Fry, "Absorption spectrum (380-700 nm) of pure water. II. Integrating cavity measurements," Appl. Opt. 36, 8710-8723 (1997).

27. W. S. Pegau, D. Gray, and J. RonaldV. Zaneveld, "Absorption and attenuation of visible and near-infrared light in water: dependence on temperature and salinity," Appl. Opt. 36, 60356046 (1997).

28. A. M. Ciotti, M. R. Lewis, and J. J. Cullen, "Assessment of the relationship between dominant cell size in natural phytoplankton communities and the spectral shape of the absorption coefficient," Limnol. Oceanogr. 47, 404-417 (2002).

29. C. S. Roesler, M. J. Perry, and K. L. Carder, "Modeling in situ phytoplankton absorption from total absorption spectra in productive inland marine waters," Limnol. Oceanogr. 34, 15011523 (1989).

30. D. Stramski, A. Bricaud, and A. Morel, "Modeling the inherent optical properties of the ocean based on the detailed composition of the planktonic community," Appl. Opt. 40, 2929-2945 (2001).

31. A. Morel, "Optical properties of pure water and pure sea water," in Optical Aspects of Oceanography, N. G. Jerlov and E. S. Nielsen, eds. (Academic, New York, 1974), pp. 1-24.

32. E. Boss and W. S. Pegau, "Relationship of light scattering at an angle in the backward direction to the backscattering coefficient," Appl. Opt. 40, 5503-5507 (2001).

33. D. Stramski, E. Boss, D. Bogucki, and K. J. Voss, "The role of seawater constituents in light backscattering in the ocean," Prog. Oceanogr. 61, 27-56 (2004).

34. E. Boss, D. Stramski, T. Bergmann, W. S. Pegau, and M. Lewis, "Why should we measure the optical backscattering coefficient?" Oceanography 17, 44-49 (2004).
35. W. H. Press, B. P. Flannery, S. A. Teukolsky, and W. T. Vetterling, in Numerical Recipes in FORTRAN: The Art of Scientific Computing, 2nd ed. (Cambridge U. Press, 1992), pp. 655675.

36. J. T. O. Kirk, Light and Photosynthesis in Aquatic Ecosystems (Cambridge U. Press, Cambridge, U.K.,1994).

37. A. Bricaud and A. Morel, "Light attenuation and scattering by phytoplanktonic cells: a theoretical modeling," Appl. Opt. 25, 571-580 (1986).

38. R. F. Davis, C. C. Moore, J. R. V. Zaneveld, and J. M. Napp, "Reducing the effects of fouling on chlorophyll estimates derived from long-term deployments of optical instruments," J. Geophys.Res. 102, 5851-5855 (1997).

39. E. Boss, M. S. Twardowski, and S. Herring, "Shape of the particulate beam attenuation spectrum and its inversion to obtain the shape of the particulate size distribution," Appl. Opt. 40, 4885-4893 (2001).

40. C. Roesler and E. Boss, "A novel ocean color inversion model: retrieval of beam attenuation and particle size distribution," Geophys. Res. Let. 30, 10.1029/2002GL016366 (2003).

41. E. Boss, E. W. S. Pegau, M. Lee, M. S. Twardowski, E. Shybanov, G. Korotaev, and F. Baratange, "The particulate backscattering ratio at LEO 15 and its use to study particles composition and distribution," J. Geophys. Res. 109, C0101410.1029/2002JC001514 (2004)

42. M. Sydor, B. D. Wolz, and A. M. Thralowa, "Spectral analysis of bulk reflectance from coastal waters: deconvolution of diffuse spectra due to scattering and absorption by coastal water," J. Coast. Res. 18, 352-361 (2002).

43. D. Pozdnyakov and H. Grassl, "Colour of Inland and Coastal Waters," (Springer, Chichester, 2003).

44. S. Maritorena, D. A. Siegel, and A. R. Peterson, "Optimization of a semianalytical ocean color model for global-scale applications," Appl. Opt. 41, 2705-2714 (2002). 